\title{
Sentir el sentido del filme: la dimensión corporal de la composición visual en la teoríade Serguéi M. Eisenstein
}

\section{Filmaren esanahia sentitzea: konposizio bisualaren gorputz-dimentsioa Sergei M. Eisensteinen teorian}

\author{
Sensing the film's sense: the embodied \\ dimensión of visual composition in the theory \\ of Serguéi M. Eisenstein
}

\section{Víctor Aertsen ${ }^{1}$}

\section{zer}

Vol. 22 - Núm. 42

ISSN: $1137-1102$

e-ISSN: $1989-631 \mathrm{X}$

DOI: $10.1387 /$ zer. 17817

pp. $137-154$

2017

Recibido el 25 de enero de 2017, aceptado el 20 de marzo de 2017.

\section{Resumen}

Estableciendo trayectorias atencionales mediante sus composiciones, las películas pueden mover corporalmente a sus espectadores, induciéndoles determinadas experiencias cinestésicas. Pero se trata de un recurso sobre el que pocos autores han reflexionado hasta la fecha. El presente texto pretende rescatar las reflexiones de Serguéi M. Eisenstein sobre dicha posibilidad expresiva del medio. Reflexiones raramente mencionadas como parte seminal de su legado teórico, dada la dispersión de su publicación, pero que resultan reveladoras para entender una dimensión estética del arte cinematográfico que comienza a penetrar la agenda investigadora de los teóricos cognitivos y fenomenológicos del cine.

Palabras clave: Cine, montaje, percepción, estética del film.

\section{Laburpena}

Filmek ikusleen gorputzak mugi ditzakete, haien arretari ibilbideak ezarriz konposizioen bidez, eta, horrela, esperientzia zinestesiko jakin batzuk eragin diezazkiekete ikusleei. Baina egile gutxik hausnartu dute baliabide horri buruz orain arte. Testu honek Sergei M. Eisensteinek baliabidearen espresio-aukera horri buruz egindako hausnarketak gogorarazi nahi ditu. Hausnarketa horiek, sakabanatuta argitaratu zirenez, oso gutxitan aipatu dira egilearen onda-

\footnotetext{
${ }^{1}$ Universidad Carlos III de Madrid, vaertsen@db.uc3m.es
} 
re teorikoaren ekarpen emankorren artean, baina esanguratsuak dira zinemaren teorizatzaile kognitiboen eta fenomenologikoen ikerketa-agendetan sartzen hasi den arte zinematografiko baten alderdi estetikoa ulertzeko.

Gako-hitzak: Zinema, muntaketa, pertzepzioa, filmaren estética.

\begin{abstract}
Establishing attentional trajectories through their visual compositions, films can move their viewers, eliciting certain kinesthetic experiences in their bodies. But few authors have thought about it until now. This text tries to rescue the reflections of Sergei M. Eisenstein on this expressive possibility of the cinematographic medium. Reflections rarely mentioned as a seminal part of his theoretical legacy, given their dispersion throughout his writings, but which are revealing to understand an aesthetic dimension of cinematographic art that starts to penetrate the research agenda of cognitive and phenomenological film theorists.
\end{abstract}

Keywords: Cinema, edition, perception, film aesthetics. 


\section{Introducción}

Tras unos melódicos créditos iniciales, las primeras imágenes de The Fortune Cookie (En bandeja de plata, Billy Wilder, 1966) sitúan al espectador en un bullicioso estadio de fútbol americano, junto a Harry Hinkle (Jack Lemmon), que retransmite el partido con su cámara al hombro desde los bordes del campo de juego. Camarógrafo experimentado, Hinckle se posiciona sucesivamente en el punto idóneo del corredor desde el que filmar con claridad el movimiento previsto del balón. Utiliza todo su cuerpo para seguir con la mirada el movimiento de los jugadores y la pelota por el espacio, torciendo, inclinando, adelantando y retrocediendo incesantemente cuerpo y cámara para mantener la acción adecuadamente encuadrada.

En un instante del juego capta cómo un corredor recibe el balón en un extremo del campo y comienza una carrera en dirección opuesta. El jugador avanza con potencia, esquivando a varios contrincantes. Hinckle se adapta con presteza, eludiendo obstáculos y retrocediendo su cuerpo para encuadrar mejor al deportista, que se aproxima paulinamente a la cámara. Aunque la acción avanza de forma precipitada, la habilidad del reportero y la cercanía del jugador consiguen que la cámara televise la fogosa jugada con admirable claridad. Hasta que el jugador es golpeado por un contrincante, que le impulsa con violencia en dirección al camarógrafo, sacándole del campo de juego. El cuerpo del deportista se abalanza sobre la cámara, sobre la mirada del espectador, asaltando físicamente al primero y perceptivamente al segundo. Y termina chocando contra el cuerpo de Hinckle, que cae dolorosamente de espaldas, forzando un respingo de los televidentes.

Poniendo al personaje interpretado por Lemmon como intermediario, la escena ejemplifica a la perfección la dimensión corporal de la relación perceptiva del espectador con toda película durante el proceso de visionado. Como Hinckle ante las jugadas que se desarrollan en el campo de juego, el espectador percibe la película con todo su cuerpo, moviéndose en una u otra dirección mientras sigue la acción a lo largo y ancho del campo de la imagen. Y a pesar de que existe una distancia ontológica insalvable entre el mundo diegético y el mundo del espectador, desde un punto de vista experiencial la brecha entre ambos universos en muchas ocasiones parece desvanecerse cuando la acción se acerca en exceso a la cámara o cuando invita al espectador a adentrarse en sus profundidades. En este sentido, la escena descrita literaliza lo que en la experiencia fílmica tan solo ocurre en sentido figurado: el choque de un objeto de la diégesis con el espectador. Un fenómeno que, a pesar de no ser factible, participa en la experiencia del espectador como posibilidad sensible.

Posicionando sucesivamente al espectador ante los personajes y los eventos representados, moviéndole a través del espacio en relación con ellos, la película establece una relación corporal entre el espectador y los elementos del universo diegético. En este sentido, la puesta en escena, en tanto que actividad creativa que produce "el posicionamiento preciso de actores y objetos ante la cámara en varias combinaciones espaciales, pictóricas y rítmicas" (Hodsdon, 1992), presenta las acciones representadas, involucrando corporalmente al espectador en el proceso. Por lo que, si entendemos la puesta en escena como "el movimiento de cuerpos en el espacio un espacio constantemente definido y redefinido por la cámara" (Martin, 2014: 45), debemos tener en cuenta que no solo son los cuerpos de los personajes los que se 
mueven en el espacio, sino también, indirectamente, el cuerpo del espectador en el espacio de visionado, al verse implicado corporalmente en el proceso de recepción estética de la obra a través de las sucesivas 'definiciones y redefiniciones' del espacio fílmico ante él.

Que la percepción es movimiento es el alegado esencial de la teoría fenomenológica de la percepción. Según Nöe (2004: 1), "percibir es una forma de actuar. La percepción no es algo que nos pasa, o que pasa en nosotros. Es algo que hacemos." Cuando vemos no representamos toda la escena en la conciencia de una vez, como ocurre en una fotografía 2 . El mundo "se hace disponible al perceptor a través del movimiento físico y la interacción” (Nöe, 2004: 1), presentándose "de una manera que está determinada por el hecho de que ocupamos un lugar tentativo y cambiante en el mundo" (Nöe, 2004: 86). Un planteamiento que Merleau-Ponty (1993: 170) avanzaba décadas atrás, al describir la percepción visual como un proceso de "palpación con los ojos", apuntando que "con la mirada disponemos de un instrumento natural comparable al bastón del ciego. La mirada obtiene más o menos de las cosas según como las interrogue, como se deslice o recueste en ellas". El mundo visual no nos es dado de una vez a la experiencia, sino de forma secuencial a medida que lo exploramos, estableciendo un diálogo atencional con el mundo que es a la vez diálogo corporal, en tanto que implica el constante movimiento del cuerpo en y por el espacio ${ }^{3}$. Un fenómeno con interesantes consecuencias en el ámbito de la estética cinematográfica.

Al posicionar sucesivamente al espectador en relación a los elementos representados, el cineasta tiene la capacidad de controlar las trayectorias atencionales de sus espectadores: los movimientos perceptivo-corporales que éstos realizan sobre la pantalla, en tanto que superficie bidimensional, y sobre el mundo diegético, en tanto que espacio tridimensional. Una posibilidad expresiva que el cine puede emplear para maximizar sus efectos corporales, especialmente los de carácter cinestésico. Pero sobre la que pocos autores han reflexionado hasta la fecha.

En este sentido, el presente texto pretende rescatar las reflexiones de Serguéi M. Eisenstein sobre las posibilidades expresivas del medio cinematográfico desde el punto de vista de las trayectorias atencionales que proponen sus composiciones visuales, en y a través de los planos. Unas reflexiones que, por encontrarse dispersas

\footnotetext{
2 A diferencia de una película o el chip de una cámara digital, la retina del ojo humano no es sensible de manera uniforme a la luz proyectada sobre ella. Por el modo en que están distribuidas sus células fotosensibles (conos y bastones) sólo puede procesar la información de color de alta resolución en su zona central (fóvea), que capta aproximadamente 2 grados de ángulo visual. A 5 grados de distancia la resolución desciende un 70\%, y a 20 grados un $90 \%$. Por lo que a cada instante percibimos en alta resolución tan solo una porción muy pequeña de la escena visual que contemplamos.

3 La información visual del espacio se codifica cuando nuestros ojos se fijan en un punto concreto de éste. Cada fijación dura un promedio de 330ms, variando su duración según la complejidad de los estímulos y las tareas visuales. Para completar la escena visual los ojos realizan incesantes rotaciones, fijando sucesivamente nuevas porciones del espacio visual en la fóvea. Cada movimiento sacádico dura un promedio de $20-50 \mathrm{~ms}$. Si el objeto de nuestra atención se encuentra a más de 30 grados, el movimiento ocular se ve acompañado por un movimiento de cabeza. Y si el objeto está fuera del campo visual (120 grados), se ve acompañado por una rotación del tronco. Debido a las limitaciones de la visión humana, somos incapaces de ver en detalle al mismo tiempo todo lo que se encuentra presente ante nuestros ojos, debiendo realizar diferentes movimientos corporales para aprehender la escena visual.
} 
a lo largo de sus escritos, no son habitualmente mencionadas como parte seminal de su legado teórico, a diferencia de sus reflexiones sobre la 'atracción cinematográfica' (Eisenstein, 1986), el 'movimiento expresivo' del actor (Eisenstein y Tretyakov, 1979) o los 'métodos de montaje' (Eisenstein, 2002). Pero que, por la lucidez y retórica del autor, resultan reveladoras e inspiradoras de cara a entender una dimensión estética del arte cinematográfico que, si bien hasta el momento desdeñada, comienza poco a poco a entrar en la agenda investigadora de la teoría fílmica (Bellour, 2013), especialmente en el ámbito de los enfoques cognitivos (Bordwell, 2000; Carroll, 2008; Grodal, 2009; Smith, 2014) y fenomenológicos (Shaviro, 1993; Sobchack, 1992, 2004; Barker, 2009).

\section{Efectos cinestésicos de los métodos de montaje}

La cuestión de la conexión directa, sin mediación intelectual, entre la actividad perceptiva y las sensaciones del espectador en la experiencia fílmica ha sido explorada por diferentes teóricos a lo largo de la historia del medio, prácticamente desde sus inicios. Anticipada en el campo de las vanguardias cinematográficas por Ricciotto Canudo y artistas visuales del llamado cine abstracto, total o integral, como Léopold Survage, Vicking Eggeling, Hans Richter, Walter Ruttmann, Fernand Léger y Henri Chomette (O'Pray, 2003; Turvey, 2011), sería la temprana teoría fílmica francesa de los años veinte la que iniciaría el primer debate teórico al respecto. Rompiendo con la tendencia imperante de comparar el nuevo medio con el teatro, escritores y cineastas como Jean Epstein, Emile Vuillermoz, Germaine Dulac, Abel Gance, René Clair, Léon Moussinac o Pierre Porte recurrieron progresivamente a la 'analogía musical' para fundamentar sus reflexiones (Abel, 1988).

Se trataba, en cualquier caso, de una serie de reflexiones impresionistas sobre las posibilidades expresivas del cine, deducidas a partir de sus propias experiencias como espectadores a través de un trabajo de introspección y elucubración, y con las cuales, además, pretendían legitimar artísticamente el nuevo medio. Pero los autores rara vez ahondaron en las estrategias concretas a disposición del cineasta y los procesos psicofísicos que los fundamentan. Y a pesar de la fecundidad de la analogía la mayoría de los teóricos se preocuparon por una sola dimensión de ésta, la cuestión del ritmo visual, que en sus manos se convirtió "en el concepto estructural general, nunca definido con precisión" (Bordwell, 1980: 145), desestimando habitualmente otras dimensiones igualmente interesantes, como la melodía visual. Pero a pesar del excesivo énfasis en el ritmo visual, algunos autores advierten pronto sobre las posibilidades melódicas de la composición visual en el cine:

Un cinegrafista debe saber escribir en la pantalla melodías para el ojo, expuestas en un movimiento preciso, con las puntuaciones convenientes y las cadencias necesarias. Deberá calcular el equilibrio de sus desarrollos, saber qué longitud puede dar a su arabesco sin arriesgarse a hacer perder a los espectadores lo que podría denominarse el sentimiento tonal de su composición. (Emile Vuillermoz, 1927, citado en Mitry, 2002: 401). 
En cualquier caso, la analogía musical sería retomada con notoriedad por Serguéi M. Eisenstein, según David Bordwell (1980: 147) “el más preciso teórico del dinamismo cinematográfico -ese proceso que constantemente empuja al espectador al éxtasis, fuera-de-la-estasis". Formalista temprano, el cineasta y teórico ruso se interesó a lo largo de su carrera teórica por el poder afectivo de la forma fílmica, es decir, las posibilidades expresivas de la forma fílmica en relación con lo representado. En este sentido, el movimiento en y entre los planos, tanto de los cuerpos representados como de las formas plásticas presentadas, sería uno de sus focos de mayor interés. Como señalaba Eisenstein (2002: 133), en un temprano texto sobre los diferentes Métodos de montaje, "la verdadera cinematografía empieza solamente en la colisión de varias modificaciones en el cine de movimientos y vibración".

En dicho texto, estirando la analogía musical, ofrece una taxonomía de posibles estrategias de edición fílmica, planteando cuatro tipos de montaje en función de la articulación de los materiales y los efectos psicofisiológicos que son susceptibles de provocar en su espectador ${ }^{4}$ : montaje métrico, rítmico, tonal y armónico. Para el autor, "el común denominador de todos estos fenómenos visuales", en palabras de Bordwell (1999: 160), “y de todos los fenómenos acústicos también, es la sensación fisiológica entrecruzada: ya no «veo» u «oigo», sino que más bien «siento»". Siendo el tipo de sensaciones que comenta el autor soviético, en esencia, de carácter cinestésico.

En el montaje métrico el criterio de construcción es la longitud absoluta de los fragmentos, dando lugar a un compás que puede "llevar a un unísono entre el «latido» del filme y el «latido» de los espectadores" (Eisenstein, 2002: 128). Un fenómeno de sincronía rítmica que "se caracteriza por un motivo rudo, la fuerza, capaz de impulsar al espectador a reproducir exteriormente la acción percibida" (Eisenstein, 2002: 133) mediante el golpeteo de un pie o el balanceo del cuerpo, produciendo en consecuencia un efecto cinestésico primitivo ${ }^{5}$. Apunta, en cualquier caso, que el compás debe ser claro para resultar efectivo, ya que "una complejidad excesiva del latido métrico produce un caos de impresiones en lugar de una clara tensión emocional" (Eisenstein, 2002: 128), resultando “indispensable para la «organización» de la impresión sensitiva" que la pulsión sea reconocible. Una advertencia que en buena medida explica la decepción tardía de los impresionistas franceses con la cuestión del ritmo fílmico, cuyas posibilidades expresivas se revelaron mucho más reducidas que en el caso del ritmo sonoro.

En segundo lugar, el montaje rítmico se construye sobre la longitud efectiva de los planos, variando la duración de cada fragmento en función del acento interno de su contenido. La longitud ya no viene determinada por la métrica, siendo "el movimiento dentro del cuadro el que impele el movimiento del montaje de cuadro a cuadro" (Eisenstein, 2002: 130, 136). Se trata de una variante matizada del montaje

\footnotetext{
${ }_{4}^{4}$ Desde sus primeras reflexiones al respecto, Eisenstein (2002: 133) advierte que "debemos también definir lo que caracteriza el efecto de las diversas formas de montaje en el complejo psicofisiológico de la persona en el fin percibido".

5 Eisenstein (2002: 133) ofrece un bello ejemplo de dicho efecto, revelado durante un visionado de su película Lo viejo y nuevo (1929): "Los distintos fragmentos son «sinónimos», conteniendo un sencillo movimiento de siega de un lado del cuadro a otro; y me produjo risa ver a los miembros más impresionables del auditorio balancearse silenciosamente de un lado a otro a una creciente proporción de velocidad, a medida que los fragmentos se aceleraban por el montaje. El efecto era el mismo que el de una banda de percusión que ejecutara un sencillo aire de marcha."
} 
métrico ${ }^{6}$, que actúa sobre el espectador de forma similar a éste, si bien su efecto "es calculado más sutilmente" en función del pulso de cada plano. Pulso que, según el autor, se constituye a partir de la implicación corporal del espectador con los movimientos puestos en escena, es decir, a partir del movimiento "de los de objetos móviles o los del ojo del espectador dirigido a lo largo de las líneas de algún objeto inmóvil". Si bien el momento trabaja únicamente con los puntos más intensos de dichos movimientos, sus acentos.

El montaje tonal, por su parte, "se basa en el característico sonido emocional del fragmento" (Eisenstein, 2002: 130, 133), entendiendo por ello no las emociones narrativas comunicadas en cada plano (la tristeza, la alegría, el miedo o el asco expresado por un personaje), sino su "tono general", que rápidamente adscribe a cualidades pictóricas de la imagen: tonalidades de luz (oscuridad, luminosidad), gráficas (angulaciones, redondeces), de color (rojo, azul), etc. Tonalidades que producen una "impresión emocional" en el espectador en función de su desarrollo ${ }^{7}$. Se trata de un "desarrollo más adelantado" del montaje rítmico, donde las cualidades pictóricas de las imágenes dominan, en su articulación, la línea afectiva producida por el pasaje completo. Desde el punto de vista afectivo el montaje tonal produce una reacción de nivel fisiológico más elevado, una respuesta "melódico-emotiva" (Eisenstein, 2002: 136) que, por desgracia, nunca llega a definir.

Por último, el autor plantea la posibilidad de un montaje armónico, que tiene plenamente en cuenta todos los estímulos del plano como elementos dominantes orgánicamente integrados. Dedica solo un par de líneas a definir dicha categoría, sumiéndola en la indeterminación. Pero a la hora de hablar de sus efectos señala que el montaje armónico, "como un nuevo chorro de puro fisiologismo, repite [el efecto del montaje métrico] en el más alto grado de intensidad, y aún lo adquiere mayor por su directa fuerza motriz" (Eisenstein, 2002: 136). Esto se debe a que los movimientos y las vibraciones de los elementos internos del plano "no impresionan ya como tonos, sino mejor como desplazamientos puramente físicos de la impresión percibida", de modo que "la sensación de desplazamiento físico es completada literalmente". El espectador ya no solo palpita con las cualidades rítmicas o tonales del montaje, sino que se ve empujado a un desplazamiento físico en sincronía con los movimientos y las vibraciones convenientemente estructurados ante él.

Ciertamente la taxonomía expuesta por Eisenstein en este texto seminal no está exenta de ambigüedades y deficiencias. Por desgracia, si bien los dos primeros métodos de montaje se explican con claridad la definición de los dos últimos resulta meramente tentativa, al tratarse de fenómenos complejos que el autor parece intuir pero todavía no ser capaz de detallar. Pero el interés demostrado por la relación afectiva entre espectador y composición visual seguirá siendo uno de los pilares fundamentales de sus divagaciones estéticas a lo largo de su carrera, pudiéndose

\footnotetext{
${ }^{6}$ Una matización que Jean Mitry (2002: 420) desarrolla años más tarde, criticando lo que entiende como el privilegio excesivo de la métrica en la reflexión sobre el ritmo de los teóricos franceses antes citados: "Un film no es rítmico porque arbitrariamente se haya decidido montar una continuidad de planos en una relación métrica determinada. El ritmo es, más que relaciones de intensidad, relaciones de intensidad en relaciones de duración. La intensidad de un plano depende de la cantidad de movimiento (físico, dramático o psicológico) que contiene, y de la duración en la cual se produce."

7 Se percibe aquí la libertad con que el autor emplea el término 'emoción', aquí usado como sinónimo de 'sensación'.
} 
encontrar entre sus diversos escritos múltiples reflexiones susceptibles de colmar este vacío inicial.

\section{El movimiento corporal a través del montaje melódico}

Desarrollando sus reflexiones iniciales sobre los métodos de montaje, en especial -si bien no de forma explícita- el montaje armónico, el director ruso se interesaría a lo largo de su carrera teórica por el movimiento perceptivo que el espectador de cualquier obra de arte realiza durante la fruición estética de ésta. Desplazamientos dinámicos de la mirada y en consecuencia del cuerpo susceptibles de inducir determinados afectos en el espectador, los cuales, en caso de concordar con los temas representados, participan en la constitución del sentido de la obra. Según Eisenstein (1986: 124):

El movimiento, fundamento de toda obra de arte, no es abstracto o aislado del tema, sino la encarnación plástica generalizada de la imagen con la cual se expresa el tema. 'Esforzándose por subir', 'expandiéndose', 'quebrado', 'bien trabado', 'rengueando', 'desenvolviéndose suavemente', 'fragmentario', 'en zigzag', son expresiones usadas para definir ese movimiento en los ejemplos más abstractos y generales. [...] Dicha línea puede contener no sólo características dinámicas sino también todo un complejo de elementos y significados fundamentales peculiares de ese tema y esa imagen.

El autor, que entiende el movimiento como el 'fundamento de toda obra de arte', considera que cada imagen debe forzar una trayectoria perceptiva que exprese las ideas representadas y contagie los afectos apropiados en su espectador. Reflexiona en este sentido sobre campos artísticos dispares, como la arquitectura y la pintura, encontrando en todos ellos no solo ejemplos significativos de trayectorias perceptivas, sino también de montajes cinematográficos avant la lettre.

Plantea por ejemplo que "a partir de un espectador en movimiento" (Eisenstein, 2014: 13) la arquitectura se articula como un montaje. En Montaje y Arquitectura apunta que en la arquitectura griega podemos encontrar "los ejemplos más perfectos de diseño de plano, cambio de plano y duración de plano (es decir, la duración de una impresión particular)" (Eisenstein, 2001: 88, 89), añadiendo que la Acrópolis de Atenas "podría también decirse que es un ejemplo perfecto de una de las películas más antiguas", dado que "es difícil imaginar una secuencia de montaje de un conjunto arquitectónico con una composición más sutil, plano a plano, que la que crean nuestras piernas paseando entre los edificios de la Acrópolis".

El comentario no solo apunta a la relación entre montaje cinematográfico y composición arquitectónica, en tanto que yuxtaposición ordenada y secuencial de planos espacio-temporales. Sino también a la relación eminentemente corporal que un complejo arquitectónico establece con su visitante, que lo percibe y siente a través del movimiento de sus piernas por el espacio, siguiendo la trayectoria perceptiva y motora que la construcción propone ${ }^{8}$. Del mismo modo que en los grandes complejos

${ }^{8}$ Una secuencialidad perceptiva que Víctor Hugo captaría, como recuerda Eisenstein, al denominar las 
arquitectónicos del pasado se hablaba de la 'trayectoria del espectador' para hacer referencia a su movimiento "por una serie de fenómenos atentamente dispuestos que absorbía ordenadamente a través del sentido de la vista" (Eisenstein, 2001: 87), en el caso del cine hace referencia a "la trayectoria imaginaria que sigue el ojo y las diferentes percepciones de un objeto en función de cómo aparece al ojo"”.

En otro ensayo habla sobre la emoción que producen las obras arquitectónicas dotadas de armonía, ofreciendo una interesante reflexión sobre las sensaciones sobre las que dicho concepto estético se articula, en el caso de la arquitectura:

Uno de los grandes méritos de las construcciones y conjuntos arquitectónicos se considera que es la transición armónica de algunas de sus formas en otras, como si algunas 'desbordaran' en otras. Esto es inmediatamente perceptible en los ejemplares más perfectos de la arquitectura. Y la dinámica de estos elementos de construcción desbordantes entre sí despiertan ese sentimiento de cautividad emocional, ese todo 'no-concreto', 'no-representativo', que un edificio verdaderamente armonioso representa para nosotros. El 'no-concreto' y 'no-representacional' en este caso de ninguna manera elimina de tal conjunto una muy bien definida 'cualidad figurativa' (Eisenstein, 1987: 77-78).

Sin perder su concreción, su cualidad figurativa, los elementos materiales y/o representativos de la obra se integran en un todo orgánico por el que el espectador se mueve formando trayectorias sentidas y con sentido. "Una piedra ya no es una piedra, sino un sistema de intersecciones de ángulos y planos en cuyo juego la base geométrica de sus formas explota" (Eisenstein, 1987: 75). Hay una buena razón para que Goethe llamara a la arquitectura 'música congelada', y es que en "la armonía del amontonamiento de sus masas" radica "el mismo singular 'baile' que está en la base de la creación de obras de música, pintura y montaje cinematográfico” (Eisenstein, 1987: 79) ${ }^{10}$. La obra arquitectónica funciona como una melodía musical que 'hace bailar' al espectador, movido corporalmente por sus formas, que percibe progresivamente con todo su cuerpo. En este sentido, para el autor la construcción de un conjunto arquitectónico, su composición, implica el "establecimiento de la melodía de futuros desbordamientos de sus formas y subdivisiones de sus articulaciones rítmicas".

Se trata de un planteamiento que aplica también a obras pictóricas, práctica artística en la que -como en el caso del cine- la implicación corporal del espectador resulta menos explícita, procurando precisamente el autor desvelar la importancia del fenómeno. Así, en sus escritos sobre El Greco nos recuerda que

catedrales medievales 'libros de piedra'.

9 También ofrece Eisenstein (2001: 87), cabe señalarlo, otra posible acepción del término en el caso del cine, menos interesante para nuestros intereses: "También hoy puede significar la trayectoria que sigue la mente a través de una multiplicidad de fenómenos, muy distantes en tiempo y espacio, agrupados en una determinada secuencia con vistas a un único concepto significativo; diversas impresiones que pasan ante un espectador inmóvil."

${ }^{10}$ En otro texto Eisenstein hace referencia a esta misma sentencia del poeta alemán: "El concepto de un fenómeno realmente estático en una función dinámica está dialécticamente representado en las acertadas palabras de Goethe: [...] La arquitectura es una música helada" (Eisenstein S. M., 2002: 104). 
si el espectador no puede desplazarse [como en la arquitectura], entonces hay que reunir en un punto único los elementos que en la realidad se encuentran dispersos, esparcidos, inabarcables para una única mirada, pero que el autor debe yuxtaponer, porque sólo abarcando todos esos elementos accederá el espectador a una impresión del objeto o - sobre todo - a la impresión que el autor quiere inducir cuando transforma así las relaciones reales, lo que quiere trazar para la percepción (Eisenstein, 2014: 13).

A través de la yuxtaposición creativa de los diferentes planos visuales que solicitan la atención del espectador, el autor no solo puede representar las relaciones entre los elementos pintados, sino producir impresiones que hagan sensibles las dinámicas de dichas relaciones. En otro texto, enfatizando la importancia de la naturaleza esencialmente dialéctica del arte, nos ilumina sobre las posibilidades dinámicas de un dibujo:

El ojo sigue la dirección de un elemento en la pintura y retiene una impresión visual, que choca con la impresión derivada de seguir la dirección de un segundo elemento. El conflicto de estas direcciones forma el efecto dinámico al percibir el conjunto (Eisenstein, 2002: 106) ${ }^{11}$.

Es la trayectoria del ojo sobre el lienzo, determinada por su configuración plástica, marca la experiencia estética de ésta, en forma de sensaciones (impresiones) en diálogo (conflicto). Elucubraciones que continúa en El sentido del cine, donde señala que "el todo inmóvil de un cuadro y sus partes no entran en la percepción simultáneamente" (Eisenstein, 1986: 141-142), sino que, bien al contrario,

hay generalmente en una pintura algo que atrae la atención antes que todos los demás elementos. Desde allí la atención se mueve siguiendo la trayectoria deseada por el artista. Esta trayectoria puede describirse con una línea de movimiento, con un sendero de matices graduados o con la agrupación o 'juego' de personajes. ${ }^{12}$

\footnotetext{
${ }^{11}$ El ensayo comienza también con una interesante cita de Goethe, que sirve de guía para su desarrollo teórico: "En la naturaleza nunca vemos nada aislado, sino que cada cosa está en conexión con algo más que está delante suyo, a su lado, debajo o encima." (Eisenstein S. M., 2002: 106)

${ }^{12}$ Sobre el movimiento de la atención del espectador 'siguiendo la trayectoria deseada por el artista', si bien desde un punto de vista narrativo antes que sensacional, Eisenstein (1986: 141) evoca un recurso reseñable de la tradición pictórica occidental: "Es interesante señalar aquí que en un período anterior del arte gráfico, cuando el concepto de 'trayectoria de la vista' era aún difícilmente separable de una imagen física, los caminos se introducían en los cuadros como caminos para la vista, representaciones concretas de caminos, a cuyo largo se distribuían los acontecimientos que el artista deseaba describir en cierto orden. [...] Así, el cuadro de Dirk Bouts El sueño de Elias en el desierto, muestra a Elias durmiendo en primer término, mientras otro Elias se aleja por un camino que se interna serpenteando en el fondo del cuadro."
} 
Dos ejemplos pictóricos ofrecidos por Eisenstein ayudan a ilustrar la importancia que el cineasta ruso otorga a la trayectoria atencional impuesta por la composición plástica y sus resonancias sensitivas. En primer lugar, su descripción de la estrategia compositiva empleada por Vasili Súrikov en su obra Paso de Suvórov por los Alpes, que retrata el despeñamiento de un grupo de soldados por un precipicio montañoso. Eisenstein (2014: 55) avisa que el cuadro no se considera una de las mejores obras del pintor ruso, pero aun así resulta reseñable por haberlo dotado de "un poderosísimo efecto dinámico en la caída de los personajes al abismo", algo que consigue gracias a la línea general de la composición, que guía nuestra mirada de derecha hacia izquierda y de arriba hacia abajo, en diagonal, para acabar rompiéndose a medio camino, cayendo en picado hacia la parte inferior del cuadro, donde se abre el abismo. Según Eisenstein (2014: 57):

\begin{abstract}
El ojo, que ha recorrido rápidamente esta diagonal, se detiene de pronto. $\mathrm{Su}$ camino queda interrumpido. Está desorientado. [...] Se alcanza la sensación de caída en el abismo gracias a una línea de composición y de articulaciones generales. Es la diagonal que parece correr del ángulo superior izquierdo [...] al ángulo inferior derecho [...] y que, una vez alcanzado el centro de la tela, es retenida un instante, antes de virar bruscamente en una línea vertical que la hace caer hacia abajo, más allá del marco. Es decir, un efecto de fractura del movimiento acompañado de una caída desenfrenada en vertical [...]. Esto es lo que pasa con la línea de composición de las secciones generales.
\end{abstract}

El cuadro expresa su temática no solo de forma icónica, por los elementos representados en su interior, sino también de forma compositiva, a partir de la relación corporal que establece con el perceptor, que se involucra en su movimiento. Es decir, la obra "reproduce totalmente en su geometría [...] el juego de movimientos (de las acciones exteriores)" (Eisenstein, 2014: 58) que representa, a saber: la caída de los soldados por el precipicio que se abre a sus pies, que el espectador siente corporalmente a través de su participación perceptiva con las formas de la obra. Además, entre la multitud de soldados en caída destacan tres figuras, posicionadas sucesivamente al comienzo, en el punto central y al final de la línea quebrada de composición, y cuya trayectoria, seguida perceptivamente por el espectador, condiciona la lectura que se hace del cuadro, convertido en ejemplo de montaje cinematográfico:

Los soldados uno, dos y tres se leen como tres planos sucesivos de una misma acción: 1) el personaje inclinado hacia atrás; 2) el soldado inclinado hacia delante, y 3) el cuerpo del soldado que se escurre bajo sí mismo (la figura de un cuerpo que resbala bajo sus propios brazos, y no una elevación de los brazos de ese personaje en escorzo, como se podría interpretar erróneamente), cosas todas ellas admirables por su expresividad. Esas tres fases se funden bruscamente en una. Con especial fuerza en los personajes dos y tres idénticos salvo en la posición de sus brazos - , que transmiten, con absoluta 
precisión, no ya la sensación de brazos que se elevan, sino la de un cuerpo que se escurre bajo los brazos. El borde del cuadro, el cual corta en dos a un personaje y engulle a medias a un segundo, es utilizado de manera no menos cinematográfica (Eisenstein, 2014: 58).

Siguiendo la trayectoria perceptiva propuesta por la composición, el espectador es invitado a acompañar en su inevitable caída a esas tres figuras, que juntas componen -como en una secuencia de montaje cinematográfico- el "drama del soldado" (Eisenstein, 2014: 58). Pero, además, dado que el movimiento perceptivo resuena en todo el cuerpo del espectador, aunque éste no se desplace, la sensación de precipitación inexorable que la composición consigue contagiar dota de una especial fuerza expresiva a la imagen de esa tercera figura, que a pesar de aparecer con los brazos en alto no aparenta estar alzándolas en su caída, sino cayendo en picado, para ser engullido por el abismo del marco.

Por otro lado, en su texto Piranesi, or the Fluidity of Forms, el director ruso analiza de forma similar la obra de Piranesi Carcere oscura, integrada en la serie Opere varie di Architettura. El autor se muestra fascinado por el modo en que Piranesi construye obras caracterizadas por presentar perspectivas donde los sucesivos planos espaciales superpuestos constantemente interrumpen la progresión de la profundidad. En Carceri, el movimiento del ojo hacia la profundidad del espacio representado siempre es interrumpido por un puente, una columna, un arco u otro elemento arquitectónico interpuesto. En todos los casos, detrás de la columna o del puente en cuestión el movimiento de la perspectiva vuelve a iniciarse. Pero no coincide con la escala del movimiento anterior, que el ojo del espectador sigue por inercia, sino en una escala mucho más reducida de lo sugerido y esperado. Esta forma de componer la obra, según Eisenstein, produce un efecto obvio de profundidad extrema: el espectador aprehende la imagen como un espacio dramáticamente prolongado, que empuja la mirada hacia el fondo. Pero la composición también produce otro efecto más fascinante para Eisenstein (1987: 86-87), una sensación de choque o explosión formal, por la que el espectador:

siente como si la construcción arqueada sugerida 'está explotando' fuera de su escala natural sugerida hacia una escala cualitativamente diferente - hacia una escala de mayor intensidad (en el caso dado, el movimiento normal propuesto en el espacio está explotando 'fuera de sí mismo'). Esta es la fuente del inesperado salto cualitativo en escala y espacio. Y la serie de movimientos espaciales hacia las profundidades cortada por columnas y arcos se construye como una sucesión de enlaces rotos de espacios independientes encadenados no en términos de una sola perspectiva ininterrumpida, sino como una secuencia de colisiones de espacios cuya profundidad es de una intensidad cualitativamente diferente. 
La composición condiciona un determinado trayecto de la mirada del espectador por el espacio de la imagen -bidimensional-y del universo que ésta representa -tridimensional-, movimiento que produce una determinada experiencia en el observador en función de sus cualidades. En este caso, frente a otras imágenes fluidas y armónicas, el grabado de Piranesi crea la sensación de un avance inexorable pero constantemente bloqueado o sacudido hacia las profundidades del espacio, como si el espectador chocase sucesivamente con obstáculos en constante progresión hacia el fondo. Mediante su composición, la obra de Piranesi sumerge o ataca incesantemente al espectador:

Puentes engendran nuevos puentes. Columnas nuevas columnas. Y así ad infinitum. Hasta donde el ojo puede seguir. [...] Un plano emerge tras otro plano, y mediante un sistema de explosiones sumerge [al observador] cada vez más en las profundidades. O a través de un sistema de nuevos primeros planos que surgen continuamente, cuyo desplazamiento precipitan hacia adelante desde el grabado, atacando al espectador (Eisenstein, 1987: 85)

En el mismo texto, compara esta obra de Piranesi con los paisajes verticales de la pintura china y japonesa, en los que "también una remarcable sensación de ascenso es conseguido" (Eisenstein, 1987: 87-88), si bien en este caso "es un ascenso sereno, solemne hacia las iluminadas alturas", mientras que en Piranesi "todo es dinamismo, torbellino, un ritmo furioso que arrastra a las profundidades y hacia el interior". En ambos casos el "efecto emocional [...] excede los límites del efecto realista común", dando lugar a "un efecto de éxtasis que va más allá de los límites del simple reflejo real de la apariencia de los fenómenos". Un efecto extático que expresa cierto "quietismo panteísta" en los paisajes asiáticos y una enérgica "explosividad" en la obra del italiano.

El quietismo trata de reconciliar la oposición [entre elementos] a través de la disolución de uno en el otro [...], devolviendo y conduciendo los saltos explosivos en un flujo suave, unitario. El otro tipo de éxtasis actúa de una manera diferente: afilando cada uno de los contrastes al máximo, trata de forzar en el punto más álgido de esta tensión que penetren entre sí, y a través de esto eleva su dinamismo reducido a los límites más altos (Eisenstein, 1987: 88).

Para Eisenstein, la forma pictórica 'pone en movimiento' las obras: en el caso de las obras asiáticas, las hace fluir, disolviéndose sus elementos entre sí según se desplaza la mirada del espectador sobre ellos; en el caso de Piranesi, las hace explotar, penetrando sus elementos violentamente unos en otros. La fruición estética de estas obras provoca una reacción dinámica en el espectador, cuya atención es dirigida por sus formas, las cuales acaban por hacerle flotar o explotar, según se organicen sus tensiones internas. 
De modo que el espectador de un cuadro, una escultura, un edificio o el fotograma de una película no recibe la imagen presente ante él toda de golpe, sino que la explora secuencialmente en función de la estructura plástica que presenta. En este sentido, entiende el autor que:

El arte de la composición plástica consiste en llevar la atención del espectador por el camino y orden exactos prescritos por el autor. Esto se aplica al movimiento de la vista sobre la superficie de un lienzo, si la composición se expresa pictóricamente, o sobre la superficie de la pantalla, si se trata de una toma fílmica (Eisenstein, 1986: 141).

De sus palabras se deduce que no hay discontinuidad entre este método de análisis y su teoría del montaje y la composición fílmica. "Para Eisenstein", según Bordwell (1999: 211), "la tarea básica de composición visual consiste en establecer una senda para el ojo del espectador de acuerdo con el tema. Así, las cualidades perceptivas del plano permiten una serie de posibilidades emocionales". Al movimiento de la vista sobre la pantalla cinematográfica, y sus consecuencias para la experiencia fílmica del espectador, dedica buena parte de su obra El sentido del cine.

Plantea allí la idea del montaje vertical, donde imagen y sonido se complementan en un todo orgánico, de tal modo que "encontramos una completa correspondencia entre el movimiento de la música y el movimiento de la vista sobre las líneas de la composición plástica” (Eisenstein, 1986: 132). Pero, más allá de la coordinación con la música, interesa aquí exponer las ideas que el director ruso ofrece sobre el poder expresivo de la composición y el montaje cinematográfico desde el punto de vista de las trayectorias atencionales solicitadas al espectador.

Ofrece en este sentido un ejemplo de su película Alexander Nevsky (1938), concretamente las primeras imágenes de la escena de la 'batalla del Hielo', donde el ejército ruso espera al teutónico. Resulta revelador el modo en que especula sobre la trayectoria seguida por la mirada del espectador en las primeras doce tomas de la escena, a las que dedica el análisis. Según el director, plásticamente cada imagen "tiene a la izquierda un 'acorde' plástico más sólido y pesado, que atrae la atención de la vista en primer lugar" (Eisenstein, 1986: 143-144), de modo que "en todo el sistema plástico de los cuadros el lado izquierdo es 'antes', mientras que el derecho es 'después', porque la vista ha sido dirigida en una forma particular de izquierda a derecha, a través de cada uno de aquéllos". Este efecto es potenciado por lo que denomina el "indicador dramático" de la escena, la dirección hacia la que miran los personajes representados en las imágenes, en este caso hacia la derecha de la composición. Todos menos uno, cuya mirada hacia la izquierda "remplaza lo que hubiera sido una serie monótona por una serie nerviosa" (Eisenstein, 1986: 146), funcionando por lo tanto como un contrapunto que, paradójicamente, refuerza -como un elástico- la dirección general de nuestra atención hacia la derecha ${ }^{13}$.

\footnotetext{
${ }^{13}$ Las especulaciones sobre la trayectoria de la mirada de los espectadores que Eisenstein plantea para la escena de Alexander Nevsky (1938) han sido corroboradas experimentalmente por Tim J. Smith (2014). El autor forma parte de un grupo de investigadores dedicados al estudio empírico, mediante
} 
Psicológicamente, esta estructura pictórica, al ser aprehendida por el espectador en forma de movimientos separados de la vista, produce "una sensación de algo a la izquierda luchando 'con toda su alma' hacia algún lugar a la derecha" (147). La forma crea una intensa tensión entre los dos extremos de la pantalla, que espacializan los polos de la batalla, el ocupado por el ejército ruso -izquierda-, y el que deberá ocupar el ejército prusiano -derecha-. Pero las elucubraciones de Eisenstein (1986, 155) van más allá:

Si intentamos leer este gráfico emocionalmente, junto con el contenido temático de la secuencia, comparándolos entre sí, hallaremos una curva 'sismográfica' correspondiente a cierto proceso y ritmo de expectación inquieta. Comenzando con un estado de relativa calma, se desenvuelve en un creciente movimiento ascendente que puede ser leído como un lapso de tensión y espera. Cuando esta tensión se acerca a su punto culminante, hay una descarga repentina, una caída vertical: como un suspiro de alivio. La línea [... del movimiento ocular] reproduce muy claramente el estado de "contener el aliento', reteniéndolo hasta que el pecho está a punto de estallar - no sólo por creciente inspiración de aire sino también por la creciente emoción que va ligada al acto físico. 'En cualquier momento aparecerá ahora el enemigo en el horizonte'. Y después: 'No, todavía no asoma' - y uno suspira aliviado: el pecho que se ensancha, se contrae de pronto al exhalar profundamente.

Por el movimiento atencional que induce, la escena produce una sensación esencialmente corporal en el espectador, una sensación de 'expectación inquieta' que mantiene al espectador en un suspenso irregular, con momentos de tensión -ascenso palatino de la música y la mirada- y distención -caída brusca-. Una estructura que se repite progresivamente:

Y así avanza todo el proceso, rítmicamente, repitiéndose invariablemente con la misma monotonía que hace tan insoportable el 'suspenso' para quienes lo experimentan. Así descifrado, nuestro gráfico de curvas ascensiones, de caídas y de resonancias horizontales, puede considerarse justamente como la meta a alcanzar, la corporeización de la imagen que amalgama el proceso de cierto estado de 'suspenso' angustioso (Eisenstein, 1986, 155).

Suspenso que acabará por estallar cuando aparezca el ejército esperado, dispuesto para la batalla.

dispositivos de seguimiento de la mirada (eye-tracking), de los procesos atencionales implicados en el visionado fílmico. Sus intereses se fijan en los procesos puramente atencionales, analizando fenómenos como la 'sincronía atencional' (attentional synchrony) o el 'sesgo central' (center bias) (Smith, 2013), así como los factores endógenos y exógenos susceptibles de captar la atención de los espectadores (Mital, Smith, Hill y Henderson, 2011). 


\section{Conclusiones}

A pesar de su dispersión a lo largo de diversos textos, las palabras de Eisenstein aquí anotadas componen una interesante reflexión sobre la capacidad del medio cinematográfico de inducir sensaciones cinestésicas en su espectador a través de las trayectorias atencionales que sus composiciones y su montaje solicitan que desarrolle.

En cualquier caso, el autor no solo defiende dicho potencial. De forma implícita, sus textos plantean dos ejes complementarios sobre los que se pueden desarrollar las trayectorias atencionales. Por un lado, el eje perpendicular a la pantalla, que el espectador puede recorrer hacia delante (la profundidad del plano) y hacia atrás (su espacio de visionado), como señala en su análisis de Carcere oscura. Por otro, la superficie de la pantalla, pudiendo el espectador ver arrastrada su mirada a lo alto y ancho de ésta, como plantea al hablar de Paso de Suvórov por los Alpes, la pintura china o Alexander Nevsky. Advirtiendo además sobre las condiciones necesarias para que las composiciones en cada eje resulten efectivas: la sensación de tridimensionalidad o profundidad del espacio representado, en el caso del eje perpendicular; y la amplitud de la superficie compositiva, en el caso del eje paralelo.

Pero además, sus escritos resultan reveladores por el modo en que exponen los posibles efectos que dichas trayectorias pueden producir en sus espectadores. Efectos condicionados por el eje en el que se desarrollan, por las cualidades de cada una de las trayectorias planteadas, y por la relación dialéctica de éstas con las trayectorias aledañas, es decir, las trayectorias con las que se vincula. Se trata de fenómenos intensamente cinestésicos, de caída (Suvórov), elevación (pintura asiática), asalto, inmersión (Carcere) e incluso suspensión corporal (Nevsky), cuya existencia el director avala, al describir sus propias experiencias estéticas, y cuyo significado ilumina, desvelando el modo en que las trayectorias propuestas y las sensaciones inducidas participan a la hora de crear el mensaje de la obra.

En este sentido, sus ejemplos no solo resultan reveladores para entender este tipo de vinculación afectiva del espectador con la obra audiovisual, sino que ofrecen herramientas conceptuales que pueden ayudar a la descripción de la experiencia sensible del espectador, de los elementos formales de una película y del sentido global de la obra. 


\section{Referencias bibliográficas}

Abel, R. (1988). French Film Theory and Criticism: A History/Anthology 19071939. Volume I: 1907-1929. Princeton: Princeton University Press.

Barker, J. M. (2009). The Tactile Eye: Touch and the Cinematic Experience. Berkeley: University of California Press.

Bellour, R. (2013). El cuerpo del cine: hipnosis, emociones, animalidades. Santander: Shangrila Textos Aparte.

Bordwell, D. (1980). The Musical Analogy. Yale French Studies, 60, 141-156. doi: $10.2307 / 2930009$

Bordwell, D. (1999). El cine de Eisenstein. Teoría y práctica. Barcelona: Paidós.

Bordwell, D. (2000). Planet Hong Kong. Popular Cinema and the Art of Entertainment. Cambridge: Harvard University Press.

Bordwell, D. y Thompson, K. (1995). El arte cinematográfico: una introducción. Barcelona: Paidós.

Carroll,N. (2008). The Philosophy of Motion Pictures. Malden: Blackwell Publishing.

Eisenstein, S. M. (1986). El sentido del filme. México: Siglo veintiuno.

Eisenstein, S. M. (1987). "Piranesi, or The Fluidity of Forms". En M. Tafuri, The Sphere and the Labyrinth. Avant-Gardes and Architecture from Piranesi to the 1970s. Camdridge: The MIT Press, pp. 65-91.

Eisenstein, S. M. (2001). Hacia una teoría del montaje. Barcelona: Paidós.

Eisenstein, S. M. (2002). Teoría y técnica cinematográficas. Madrid: Rialp.

Eisenstein, S. M. (2014). El Greco, cineasta. Barcelona: Intermedio.

Eisenstein, S. M. y Tretyakov, S. (1979). Expressive Movement. Millennium Film Journal, 3, 30-38.

Grodal, T. (2009). Embodied Visions. Evolution, Emotion, Culture, and Film. Oxford: Oxford University Press.

Hodsdon, B. (1992). The mystique of mise en scene revisited. Continuum: The Australian Journal of Media \& Culture, 5 (2). Recuperado de http://wwwmcc. murdoch.edu.au/readingroom/5.2/Hodsdon.html [Consultado: 30-3-2017]. doi:10.1080/10304319209388229

Martin, A. (2014). Mise en Scène and Film Style: From Classical Hollywood to New Media Art. Hampshire: Palgrave Macmillan. doi:10.1057/9781137269959

Merleau-Ponty, M. (1993). Fenomenología de la percepción. Barcelona: Planeta-Agostini.

Mital, P. K., Smith, T. J., Hill, R. L., y Henderson, J. M. (2011). Clustering of gaze during dynamic scene viewing is predicted by motion. Cognitive Computation, 3 (1), 5-24. doi:10.1007/s12559-010-9074-z

Mitry, J. (2002). Estética y Psicología del Cine (1. Las Estructuras). Madrid: Siglo XXI. Nöe, A. (2004). Action in Perception. Cambridge: The MIT Press.

O'Pray, M. (2003). Avant-garde Film: Forms, Themes and Passions. London: Wallflower Press.

Shaviro, S. (1993). The Cinematic Body. Minneapolis: University of Minnesota Press. Smith, T. J. (2014). Audiovisual correspondences in Sergei Eisenstein's Alexander Nevsky: a case study in viewer attention. En T. Nannicelli y P. Taberham (eds.), Cognitive Media Theory (AFI Film Reader) (pp. 85-104). London: Routledge. 
Smith, T. J. (2013). Watching You Watch Movies: Using Eye Tracking to Inform Cognitive Film Theory. En A. P. Shimamura (ed.), Psychocinematics (pp. 165-191). New York: Oxford University Press. doi:10.1093/ acprof:oso/9780199862139.003.0009

Sobchack, V. (2004). Carnal Thoughts: Embodiment and Moving Image Culture. Berkeley; Los Angeles; London: University of California Press.

Sobchack, V. (1992). The Address of the Eye. A Phenomenology of Film Experience. Princeton, New Jersey: Princeton University Press.

Turvey, M. (2011). The Filming of Modern Life. European Avant-Garde Film of the 1920s. Cambridge: The MIT Press. 